\title{
Integrated cmos rectifier for rf-powered wireless sensor network nodes
}

\author{
Mohammed Abdul Raheem Esmail Alselwi, Yan Chiew Wong, Zul Atfyi Fauzan \\ Mohammed Napiah \\ Micro and Nano Electronic (MiNE) research group, Centre for Telecommunication Research and Innovation (CeTRI) \\ Fakulti Kejuruteraan Elektronik dan Kejuruteraan Komputer (FKEKK), Universiti Teknikal Malaysia Melaka \\ Hang Tuah Jaya, 76100 Durian Tunggal, Melaka, Malaysia
}

\section{Article Info}

Article history:

Received Dec 29, 2018

Revised Mar 2, 2019

Accepted Mar 29, 2019

Keywords:
CMOS
Energy-harvesting
Rectifier
RFID
WSN

WSN

\begin{abstract}
This article presents a review of the CMOS rectifier for radio frequency energy harvesting application. The on-chip rectifier converts the ambient low-power radio frequency signal coming to antenna to useable DC voltage that recharges energy to wireless sensor network (WSN) nodes and radiofrequency identification (RFID) tags, therefore the rectifier is the most important part of the radio frequency energy harvesting system. The impedance matching network maximizes power transfer from antenna to rectifier. The design and comparison between the simulation results of oneand multi-stage differential drive cross connected rectifier (DDCCR) at the operating frequencies of $2.44 \mathrm{GHz}$, and $28 \mathrm{GHz}$ show the output voltage of the multi-stage rectifier doubles at each added stage and power conversion efficiency (PCE) of rectifier at $2.44 \mathrm{GHz}$ was higher than $28 \mathrm{GHz}$. The (DDCCR) rectifier is the most efficient rectifier topology to date and is used widely for passive WSN nodes and RFID tags.
\end{abstract}

Copyright $\odot 2019$ Institute of Advanced Engineering and Science. All rights reserved.

\section{Corresponding Author:}

Yan Chiew Wong,

Micro and Nano Electronic (MiNE) Research Group,

Centre for Telecommunication Research and Innovation,

Fakulti Kejuruteraan Elektronik dan Kejuruteraan Komputer,

Universiti Teknikal Malaysia Melaka,

Hang Tuah Jaya, 76100 Durian Tunggal, Melaka, Malaysia.

Email: ycwong@utem.edu.my

\section{INTRODUCTION}

An on-chip rectifier is semiconductors bsed device of a size of a few square microns. It is a component built into the radio frequency energy harvester converts AC from RF signal coming to antenna to useful DC voltage. Rectifier is the most important component of the RF energy harvesting system block diagram because the rectifier converts $\mathrm{AC}$ power to the $\mathrm{DC}$ voltage required to recharge energy to applications such as the WSN nodes. CMOS stands for Complementary Metal Oxide Semiconductor, and it's a technology builds integrated circuits. CMOS is a preferable technology for integrating the rectifier circuit on chip. CMOS technology is the most efficient to date and has superior benefits. The CMOS circuit has less power consumption, a wider operating temperature range and is better protected against noise. Battery replacement and maintenance are difficult if not impossible in the WSN nodes and the output power of the on-chip rectifier is less than the operating energy of the WSN node in the wireless power transfer domain. The output power of rectifier should be equal or more than the energy consumption of sensor node for the sensor to be capable to operate perpetually. Wireless power transfer is a new technology and an independent scientific field consist mainly of transmitter and receiver subfields, and the receiver is such that the radio frequency energy harvesting system discussed in this article focuses on WSN networks. The simulation of 
DDCC rectifier circuit was performed using SilterraC18G PDK (Process Design Kit) in a standard $0.18 \mu \mathrm{m}$ CMOS technology. RF Energy harvesting (RFEH) is a green technology helps preserve the environment by eleminating the use of batteries and recycling the ambient RF waves using RF energy harvesting system.

An on-chip CMOS rectifier is a miniaturized device based on semiconductors. The CMOS rectifier converts the small amount of power dedicated or small amount of-voltage ambient signal into a useful DC voltage for replenishing energy to microsystem applications. The CMOS differential cross connected rectifier is the most efficient so far and is used widely for radio frequency energy harvesting applications such as WSN nodes and RFID tags. The various technologies of modern RF tramsmitters send lots of power into the air, and in free space the RF wave carries both energy and information. Wireless energy reception is fundamentally different from wireless information reception. The RF signal uses energy to propagate information in free space between antennas. The reception unit can be active or semi passive with power source such as battery, or passive tage which is smaller in size because it contains no battery. RF signal come from analog RF dedicated source such as any RF power transmitter and RFID reader and from ambient RF sources such as radio mast, TV tower, wireless router, and GSM cell tower.

The on-chip CMOS rectifier of dedicated radio frequency energy harvesting system applies to RFID tags and implementable medical devices. The ambient energy harvesting system applies to recharge energy to active, and WSN nodes that spread immensely in the environment, as well as IoT devices in urban and semi urban areas and these kind of applications require little amount of energy to operate and the required energy can be harvested as these kind of applications increase enormously nowadays. Since the RF signal carries energy and information, the RF energy harvester and the sensor receiver share the same antenna as in Figure 1.

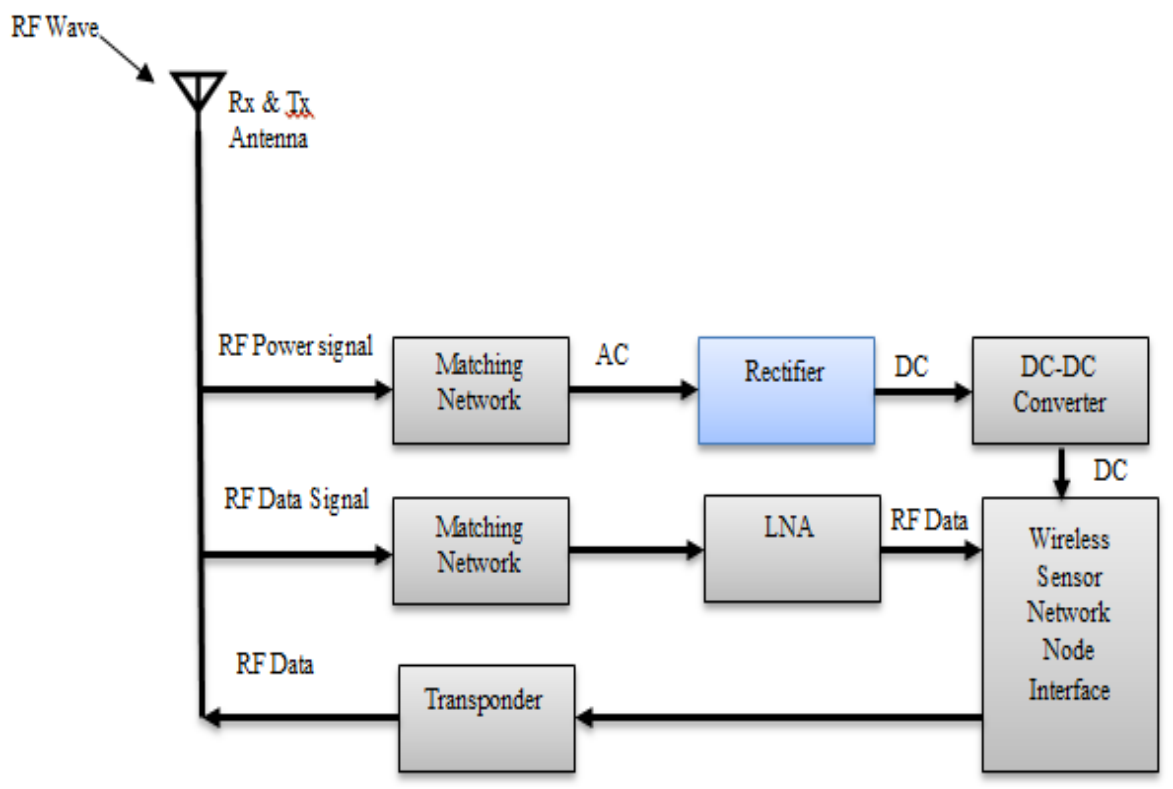

Figure 1. WSN system with RF energy harvester block diagram

On Chip Rectifier Power Conversion Efficiency $\eta$ is defined as the ratio of DC output power to the AC input power from the antenna. $\eta=\frac{P_{\text {out }}(\mathrm{DC})}{\mathrm{P}_{\text {in }}(\mathrm{AC})} \times 100 \%, \mathrm{P}_{\text {out }}=\frac{\mathrm{V}_{\text {out }}^{2}}{\mathrm{R}}$, and the main challenge in designing a CMOS radio frequency energy harvesting system is the design of a rectifier circuit operating at small amount of input power, due to the bounded power of RF wave signal as the signal power must be a function of the power levels of the RF transmitter, and for safety and health reasons, FCC rules restrict RF high level power radiations. Figure 2 (a) shows conventional diode connected transistor, and Figure 2 (b) shows Complementary diode connected transistor. Rectifier types are full wave and half wave, and structures are differential rectifier and a single ended rectifier. 


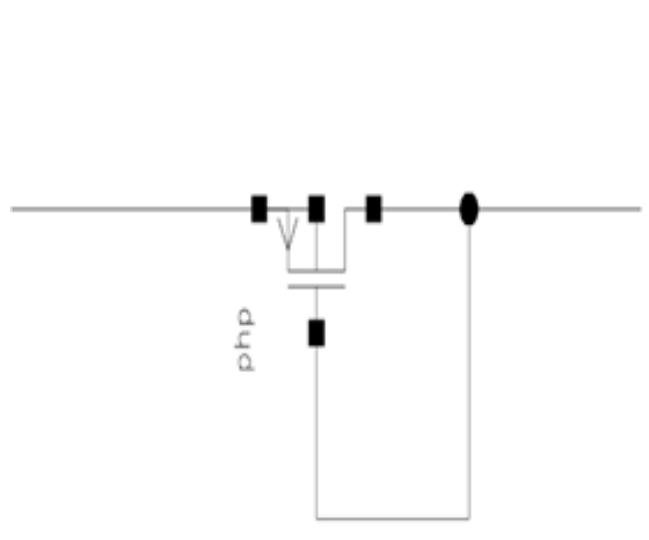

(a)

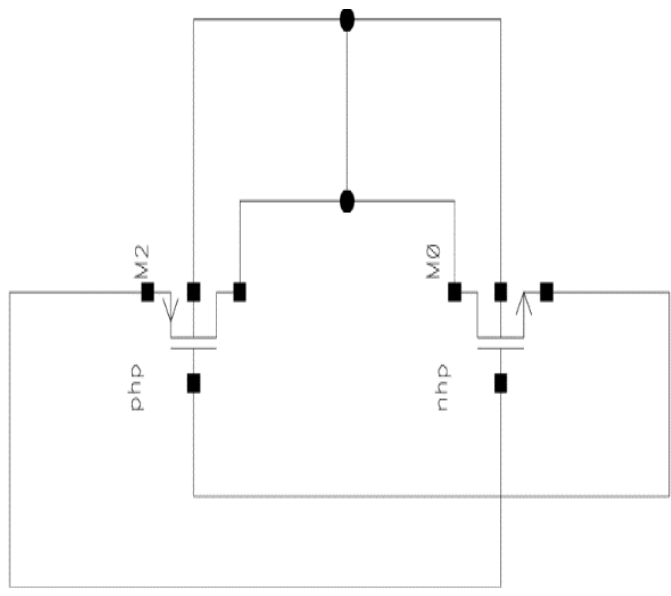

(b)

Figure 2. Diode connected transistor, (a) Conventional, (b) Complementary

The CMOS cross-connected rectifier outperforms the diode rectifier, and in our design we use the differential drive topology in which the voltage threshold cancellation scheme is implemented, and as the ambient RF power is only a few microwatts, conventional rectifier circuit reconfiguration with improvement techniques are used to increase the output voltage and efficiency of the rectifier circuit such as voltage cancellation technique in [1] the control loop circuit in [2], adaptive self biasing as in [3], improvement of the Dynamic Threshold Reduction (DTR) technique using clamper circuit that biases the gates of the pMOS diode switches through a capacitor and a diode-connected pMOS transistor[4], and implementation of impedance matching network to convert most of the available energy from the antenna to the input of threshold voltage compensation rectifier circuit [5]. In previous study [6] was found that at low input power level, the cross connected rectifier is most efficient compared to other topologies and adjusting transistors sizes (PMOS/NMOS) increases PCE. The diode-connected transistor is the fundamental unit of the on-chip CMOS rectifier and radio frequency energy harvesting solves the constraint of high-power consumption and small battery size of body area network [7]. Improving the bandwidth for the covering of wide range of telecommunication operating frequencies using an integrated transformer with ultra wideband antenna for next generation radio frequency front end [8].

The Pi impedance matching coverage can be increased at multi operating frequencies through configuring the electrical distance [9]. The PCE of rectifier is controlled by topology of rectifier circuit, input RF power, operating frequency, MOS transistor size, circuit component values such as coupling capacitors, output capacitor and load resistors. Simulation of power conversion efficiency (PCE) of conventional crossconnected rectifier topology found that PCE is $75.4 \%$ at input power of $-12.5 \mathrm{dBm}$ [10], for achieving high PCE, a low voltage threshold transistor with less leakage current is preferred [11] The transistor internal resistance is one of the causes of low PCE and it should be reduced by adjusting transistor size. The transistor's threshold voltage is subtracted from the low input voltage and reduces the PCE, therefore the implementation of voltage threshold cancellation (VTC) technique is used to provide the threshold voltage internally from the output of the rectifier for passive RFID tag [12].

The cons of VTC that as the PMOS and NMOS voltage from DC output exceeds the threshold voltage it causes high leakage current. For semi-passive and active WSN node and RFID tag, external voltage threshold cancellation is possible with battery. Reducing the threshold effect and increasing efficiency can be achieved from rectifier itself by storing energy from output of rectifier in capacitor and provide stored energy to base transistor and provide the minimum threshold voltage [13]. The new ambient energy harvesting opportunities and capabilities were studied, investigated, revealed the ambient radio frequency available at 1 $\mu \mathrm{W} / \mathrm{cm} 2$, and predicted that harvesting and recycling efficiently of ambient electromagnetic energies in the air are potential resources to recharge energy to RFID tags [14], WSN nodes [15]. A wireless communication network based on a potentially hybrid access point for far-field transfer shall add deploy a power beacon, to the current communication systems for enabling simultaneous power and data transfer. it is very intersting for evolving advanced communication and signal processing techniques for the design of efficient WPT systems [16]. The ambient RF energy sources available at $1 \mu \mathrm{W} / \mathrm{cm}^{2}$ have been revealed [17]. Recent studies have shown the ability to harvest ambient RF engergy and predicts that the efficient harvesting and recycling of ambient RF energy from the air is a potential power source helps conserving energy and is for recharging

Integrated cmos rectifier for rf-powered wireless sensor network nodes (Yan Chiew Wong) 
energy for applications requires such amount of energy, as for example ubiquotesly deployed WSN nodes $[18,19]$. More recently, the radiative WPT has sparked a keen interest in a relatively small energy distribution over a few meters to possibly several hundred meters, due to the growing need to build reliable and practical WPT systems for remote recharging energy to devices, such as RFID tags [20-22], and wireless sensors [23-28]. Table 1 Summarizes the recently released papers on CMOS rectifiers and comparison with this work, the voltage threshold cancellation (VTC) technique enables the rectifier to perform at low input power. Increasing number of stages increases output voltage but reduces efficiency.

Table 1. State of the art CMOS differential drive cross-connected rectifiers performance correlations at standard process for radio frequency energy harvesting applications

\begin{tabular}{|c|c|c|c|c|c|c|c|c|}
\hline Year/Source & $\begin{array}{l}\text { Frequency } \\
(\mathrm{Hz})\end{array}$ & Technique & $\begin{array}{c}\text { Number of } \\
\text { Stages }\end{array}$ & $\begin{array}{l}\text { Input } \\
\text { Power }\end{array}$ & $\begin{array}{l}\text { Output } \\
\text { Voltage }\end{array}$ & $\begin{array}{c}\text { Load } \\
\operatorname{RL}(\Omega)\end{array}$ & $\begin{array}{l}\text { Output } \\
\text { power }\end{array}$ & Efficiency \\
\hline Kotani, 2009 [1] & $953 \mathrm{MHz}$ & VTC & 1 & $-12.5 \mathrm{dBm}$ & $0.616 \mathrm{~V}$ & $10 \mathrm{~K}$ & $37.95 \mu \mathrm{W}$ & $67.50 \%$ \\
\hline $\begin{array}{c}\text { Stoopman, } 2014 \\
{[2]}\end{array}$ & $868 \mathrm{MHz}$ & $\begin{array}{c}\text { VTC, } \\
\text { control loop }\end{array}$ & 5 & $-17 \mathrm{dBm}$ & $1.4 \mathrm{~V}$ & $0.33 \mathrm{M}$ & $7.98 \mu \mathrm{W}$ & $40 \%$ \\
\hline Ouda, 2017 [3] & $433 \mathrm{MHz}$ & $\begin{array}{l}\text { VTC, self } \\
\text { biased }\end{array}$ & 1 & $-15.2 \mathrm{dBm}$ & $0.99 \mathrm{~V}$ & $50 \mathrm{~K}$ & $19.72 \mu \mathrm{W}$ & $65.30 \%$ \\
\hline Manal M. & $953 \mathrm{MHz}$ & & & $-16.8 \mathrm{dBm}$ & 0.38 & & $14.4 \mu \mathrm{W}^{*}$ & $70 \%$ \\
\hline Mohamed, 2018 & $402 \mathrm{MHz}$ & DTR & 1 & $-16.5 \mathrm{dBm}$ & $0.52 \mathrm{~V}$ & $10 \mathrm{~K}$ & $27 \mu \mathrm{W}^{*}$ & $86 \%$ \\
\hline This work 2018 & $\begin{array}{c}2.44 \mathrm{GHz} \\
28 \mathrm{GHz}\end{array}$ & VTC & $\begin{array}{l}7 \\
1 \\
\end{array}$ & $-16 \mathrm{dBm}$ & $\begin{array}{c}1 \mathrm{~V} \text { at }-8.6 \mathrm{dBm} \\
1 \mathrm{~V} \text { at } 2 \mathrm{dBm}\end{array}$ & $60 \mathrm{~K}$ & $\begin{array}{c}2.3 \mu \mathrm{W} \\
0.014 \mu \mathrm{W}\end{array}$ & $\begin{array}{l}58 \% \\
3.6 \% \\
\end{array}$ \\
\hline
\end{tabular}

*Estimatated value

\section{RESEARCH METHOD}

\subsection{The method of using Wireless Power Transfer (WPT)}

The method of using wireless power transfer (WPT) has the advantage of providing enough and durable power to the sensor nodes potentially for a lifetime or for a very long time. One of the approaches to increase the efficiency of WPT is to use an appropriate impedance matching network that also develops the efficiency at the front end of the dedicated WPT receiver, as well as the ambient radio frequency energy harvester, and cascading rectifier's stages increases the output DC voltage which provides a sustainable source of adequate power to the nodes of the wireless sensor network. The Cadence Virtuoso platform with the Silterra Process Design Kit (PDK) assists in the development of the schematic design of the rectifier's circuit. The load of the rectifier was reduced from $1 \mathrm{M} \Omega$ during my first simulations to $60 \mathrm{~K} \Omega$, and however this reduction decreases the output DC voltage value, but the efficiency of the rectifier increased. A $5 \mathrm{pF}$ capacitor is used to filter out the DC voltage, to reduce the voltage ripple and smoothen the DC voltage wave. Figure 3 shows schematic of conventional cross-connected rectifier. Figure 4 shows a representation of the use of WPTto recharge energy to WSN node.

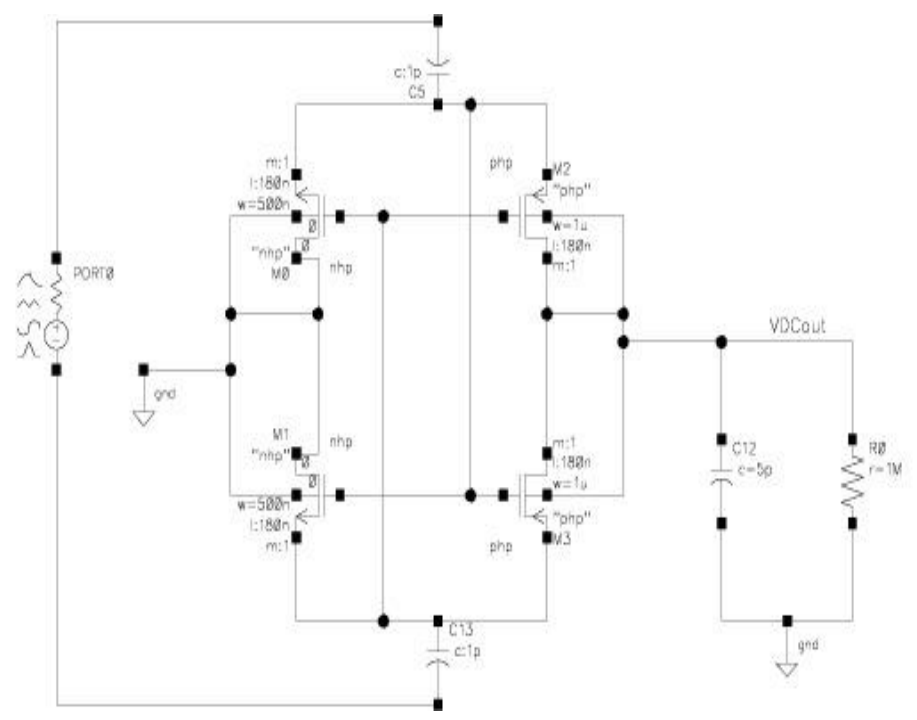

Figure 3. Schematic of conventional cross-connected rectifier 


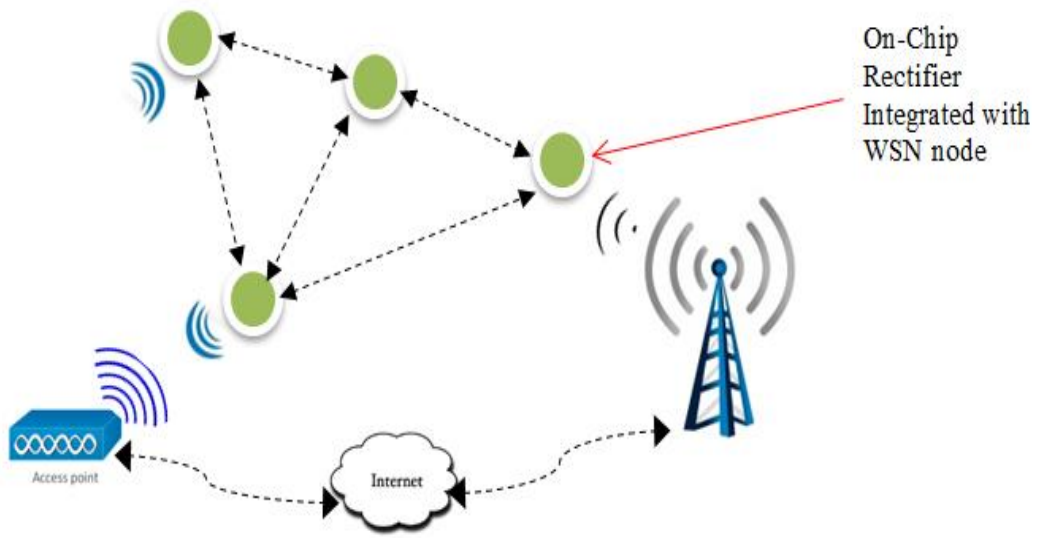

Figure 4. Symbolic representation of RF Energy transmitters Re-charging wirelessly WSN nodes

\subsection{Cadence parametric analysis tool used to optimize the input impedance of the rectifier}

Use WPT technology to provide wireless Sustainable power to recharge WSN node through RF energy harvester.

\subsection{Optimize the Harvester System and replace sensor battery}

Following the design flowchart of the CMOS circuit, we first draw the on-chip rectifier circuit in the schematic capture diagram, specifying input power, operating frequency, and load. The input power of the signal which depends on the available power in the ambient environment, ambient signal strength in urban area between $-20 \mathrm{dBm}$ to $-40 \mathrm{dBm}$ with peak $-33 \mathrm{dBm}$ at distance between 25 to 100 meters, and in our design, we define the input power as $-16 \mathrm{dBm}$, assuming the RF energy harvester near enough to an ambient RF source, and simulate for input power range from $-40 \mathrm{dBm}$ to $10 \mathrm{dBm}$, at operating frequencies of $2.44 \mathrm{GHz}$ and $28 \mathrm{GHz}$. Once the results of the schematic capture simulation have been verified, we begin the physical design of the circuit and execute the simulation and compare it with the previous simulation. Finally, the measurement of the RF and DC function of the manufactured chips and the comparison with the results of the simulation. The rectifier's stage cascade to provide the sensor node required DC voltage.

a. Design and development of the rectifier circuit: the conventional cross connected rectifier circuit is simulated with rectifier's designed input impedance and the matching network as well, and at output stage a filter capacitor of $5 \mathrm{pF}$ and a load of $60 \mathrm{~K} \Omega$.

- Single Stage rectifier: Figure 3 shows CMOS conventional differential cross connected rectifier cell made up of two pMOS transistors and two nMOS transistors connected in cross topology similarly to the counterpart of diode bridge rectifier

- Multi stage rectifier: the purpose of cascading the single stage rectifier to multistage is to double the output voltage to be as required for the application load

- Rectifier Input Impedance: is modeled as a resistor and a capacitor in parallel as shown in the $2.44 \mathrm{GHz}$ schematic in Figure 5 (a), rectifier equivalent circuit with Pi- impedance matching network at $28 \mathrm{GHz}$ in Figure 5 (b), and equivalent circuit of rectifier with cascaded L-impedance matching network in Figure 6. The rectifier input impedance is expressed as a complex number, Z_rect=R - jX_c., where $R$ and Xc are measured in $\Omega$. For multistage rectifier with $2.44 \mathrm{GHz}$ operating frequency, the input impedance matching network Z_rect=13.84-j335, and for rectifier circuit at $28 \mathrm{GHz}$ single stage rectifier, the input impedance matching network was Z_rect=49.98-j212.

- Impedance Matching Network Design: is important because the proper impedance matching circuit transfers all power from radio frequency waves coming to antenna to input rectifier and hence increases output voltage and power conversion efficiency from end to end. In Figure 6 L-matching network was shown with rectifier equivalent ciurcuit at $2.44 \mathrm{GHz}$, and in Figure 7 cascaded in series an L-matching network was shown with rectifier equivalent circuit at $28 \mathrm{GHz}$. Cascadecd L-impedance matching networks in series increases the bandwidth of impedance matching. All the designed impedance matching networks with reflection coefficient S11 is $-10 \mathrm{dBm}$ or less, as shown in Figure 7 (a) and (b).

- Load and capacitor filtering, the filter capacitor is designed as $5 \mathrm{pF}$ and Load as $60 \mathrm{~K}$ 


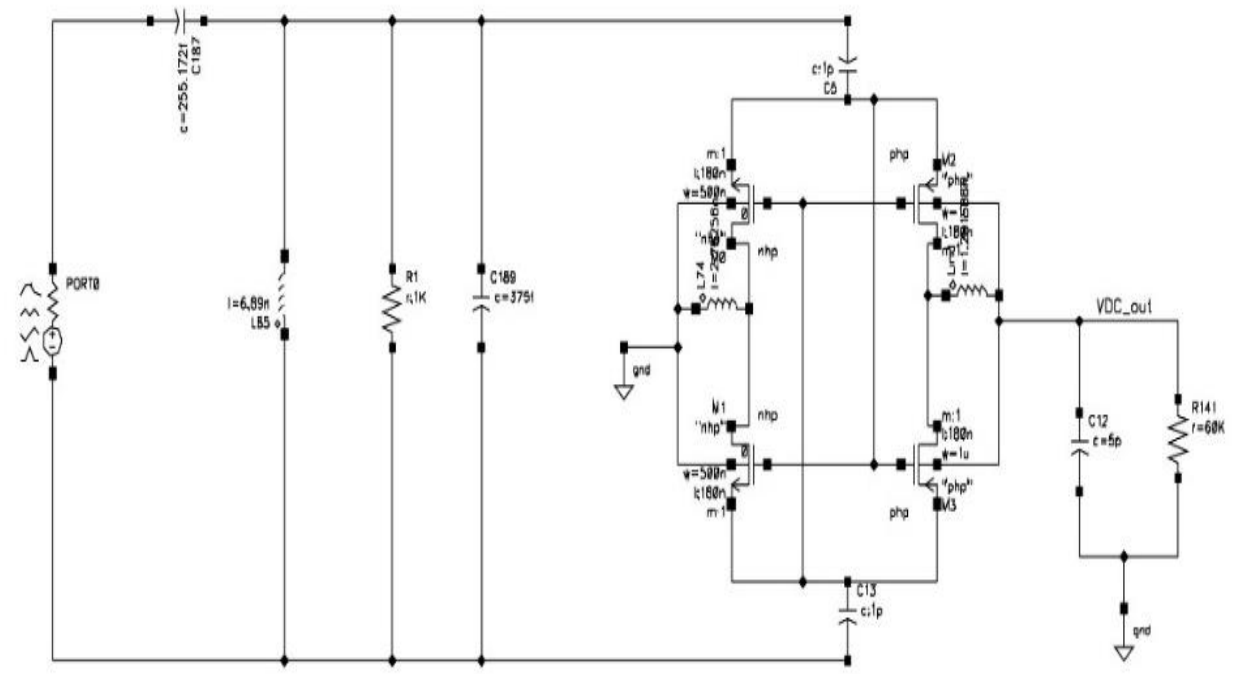

(a)

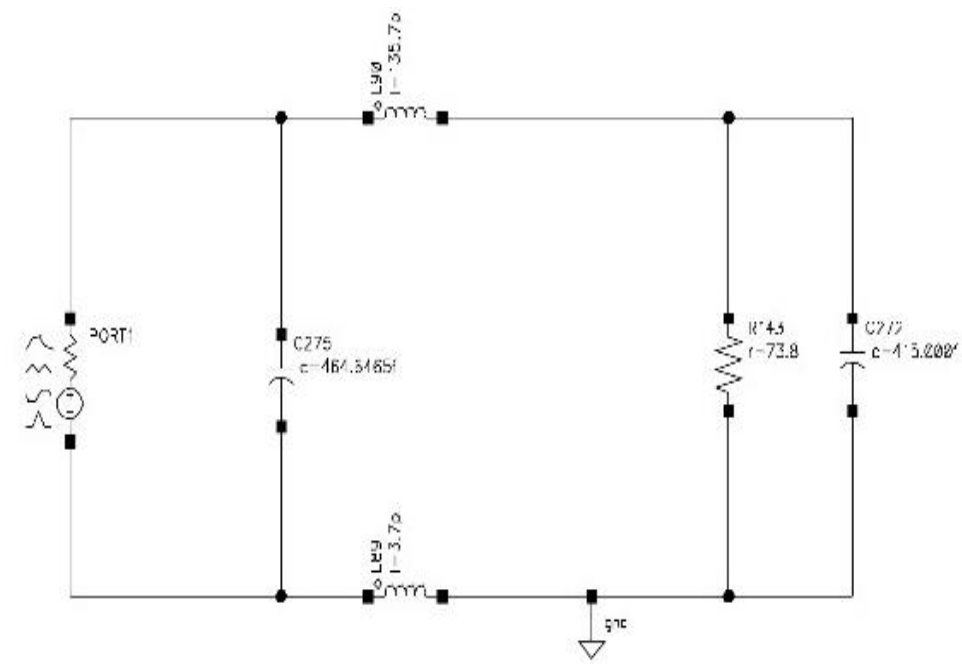

(b)

Figure 5. (a) Schematic rectifier with impedance matching network for $2.44 \mathrm{GHz}$, (b) Pi-Matching network for $28 \mathrm{GHz}$

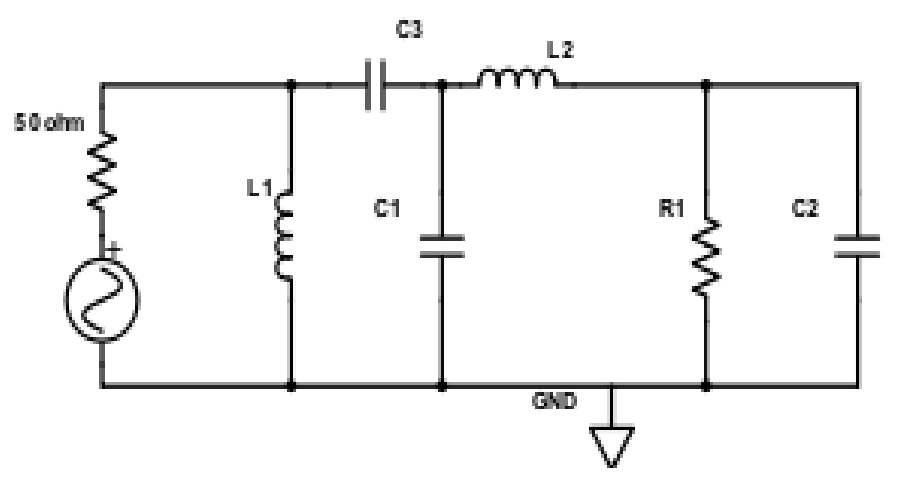

Figure 6. L-cascaded matching network 


\section{RESULTS AND ANALYSIS}

The rectifier circuits are modelled using Silterra C18G PDK with a standard $0.18 \mu \mathrm{m}$ CMOS technology. The output voltage of the rectifier proportional to the input voltage or input power at fixed load. The small value load decreases the output voltage to possible less than the voltage required for activating the sensor; therefore, the one-stage rectifier circuit is cascaded to $\mathrm{N}$-stage to produce the required output DC voltage.

\subsection{Input impedance and matching network}

The reflection coefficient $\mathrm{S} 11$ values at $2.44 \mathrm{GHz}$ is $-46 \mathrm{~dB}$, and at $28 \mathrm{GHz}$ is $-67.74 \mathrm{~dB}$ are shown in Figure 7 (a) and Figure 7 (b) respectively.

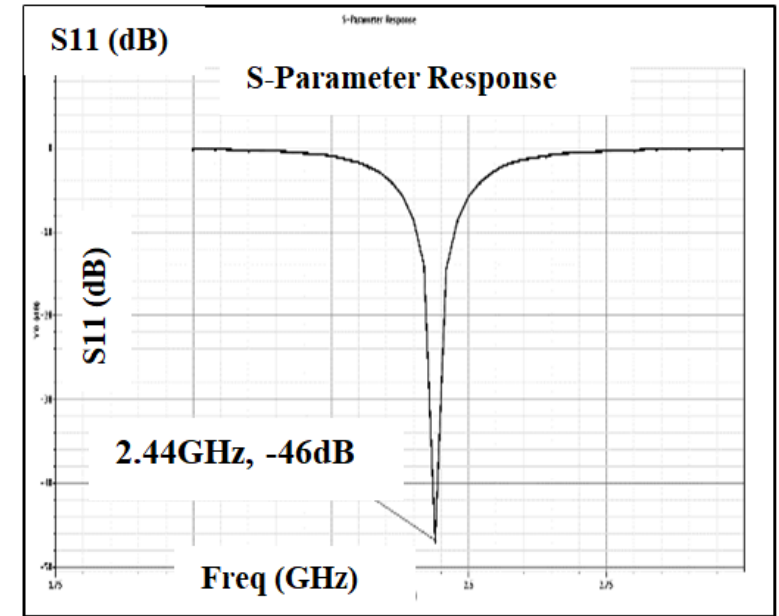

(a)

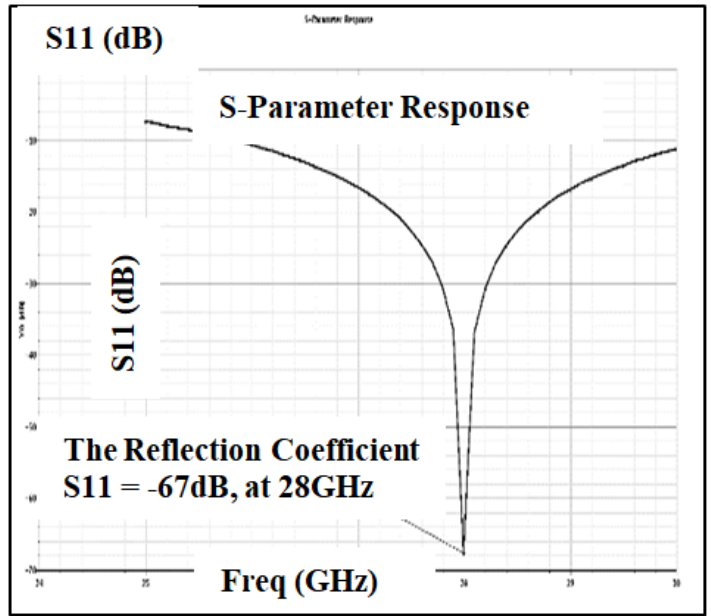

(b)

Figure 7. (a) Reflection coefficient $\mathrm{S} 11$ at $2.44 \mathrm{GHz}$, (b) Reflection coefficient $\mathrm{S} 11$ at $28 \mathrm{GHz}$

\subsection{Single-stage and multi-stage rectifier}

Single stage differential cross connected rectifier is modeled with output load resistor equals to 60 $\mathrm{K} \Omega$, and filtering capacitor is $5 \mathrm{pF}$. Input power of $-16 \mathrm{dBm}$ and operating frequency at first stimulation $2.44 \mathrm{GHz}$, and secondly $28 \mathrm{GHz}$. Figure 8 shows a DC output voltage for different input power levels. With an input power of $-16 \mathrm{dBm}$, and an output load of $60 \mathrm{~K}$, the results of the simulation show that at $2.44 \mathrm{GHz}$ the PCE of one stage rectifier circuit is $79 \%$ and with 7 stages the PCE is $58 \%$. The PCE decreases slightly with increasing number of stages due to increase of power dissipation at transistors. For a multi-stage DCCR rectifier with an operating frequency of $2.44 \mathrm{GHz}$, the reflection coefficient was $-46 \mathrm{~dB}$, and a simulation in the range of $-40 \mathrm{dBm}$ to $10 \mathrm{dBm}$ resulted to a $1 \mathrm{~V}$ at $-8.6 \mathrm{dBm}$. For the single-stage DCCR rectifier at $28 \mathrm{GHz}$ operating frequency, the reflection coefficient was $-64 \mathrm{~dB}$ and a simulation in the power input range of -40 $\mathrm{dBm}$ to $10 \mathrm{dBm}$ resulted to a $1 \mathrm{~V}$ at $2 \mathrm{dBm}$ and a maximum PCE of $3.6 \%$. As frequency increases, PCE decreases and bandwidth increases, and the impedance matching network becomes easier to design with smaller values capacitor and inductor.

The output DC voltage varies with the change of load resistor value, and the filter capacitor smotthens the ripple voltage. Figure 9 shows output DC voltage with two different loads. First load value is $10 \mathrm{~K}$ and second load value is $60 \mathrm{~K}$ and with same input power the output DC voltage at $60 \mathrm{~K}$ is higher than $10 \mathrm{~K}$. 
Periodic Steady State Analyses

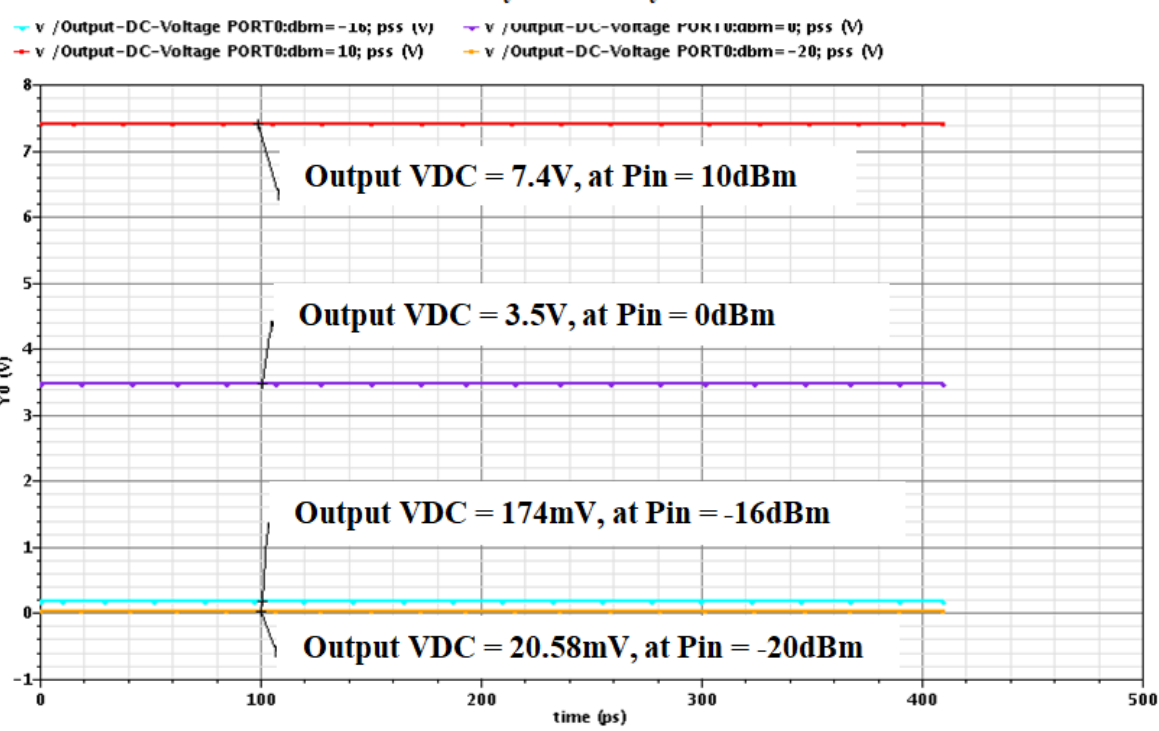

Figure 8. Output DC voltage for $2.44 \mathrm{GHz}$ at $60 \mathrm{~K}$ Load and different input power values

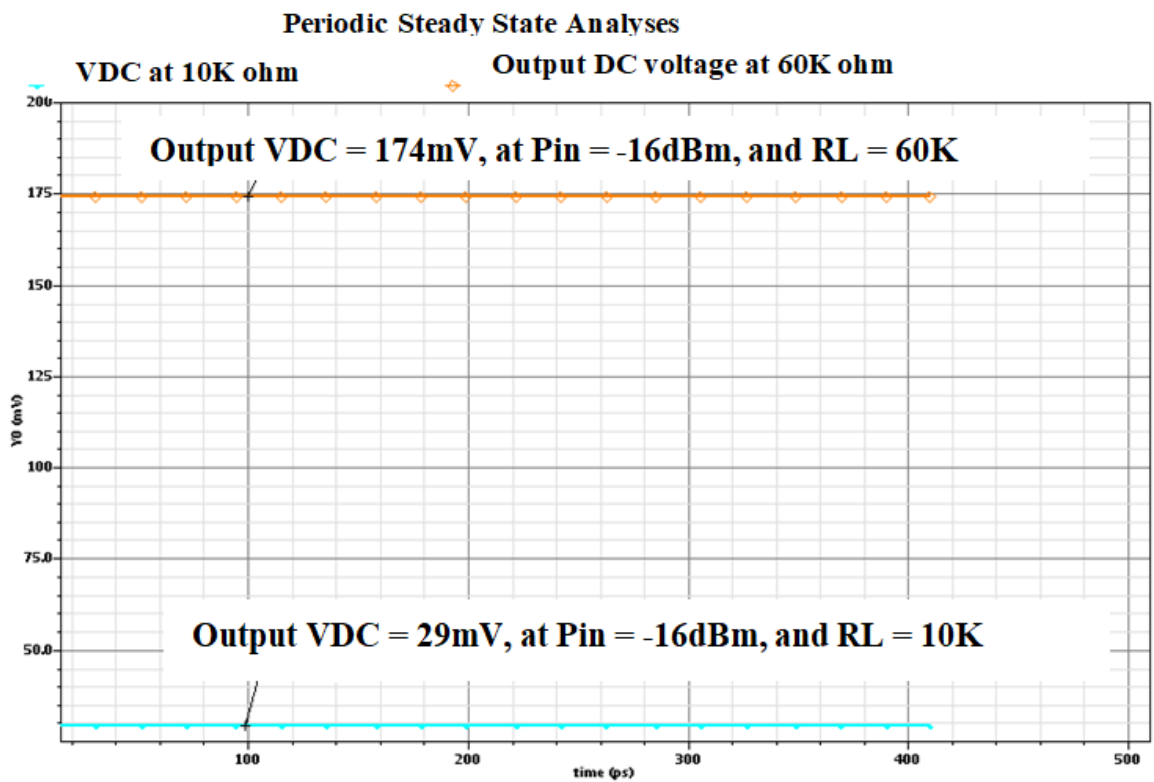

Figure 9. Output DC voltage at same Pin and different Load R, VDC $=29 \mathrm{mV}$ at RL=10K and $174 \mathrm{mV}$ at $\mathrm{RL}=60 \mathrm{~K}$

\section{CONCLUSION}

The design of CMOS rectifier for energy harvesting from dedicated and ambient radiofrequency energy sources was reviewed. The use of the harvested energy to recharge a WSN node is a feasible technology and applies to radio frequency identification tags, internet of things and implementable medical devices. The power conversion efficiency of the on-chip differential drive cross connected rectifier is higher at $2.44 \mathrm{GHz}$ than $28 \mathrm{GHz}$. Wideband impedance matching networks have been designed and optimized for a reflection coefficient of less than $-10 \mathrm{dBm}$ for a differential cross connected rectifier for operating frequencies of $2.44 \mathrm{GHz}$ and $28 \mathrm{GHz}$. Simulation with an input power range of -40 to $10 \mathrm{dBm}$ showed an increase in the rectifier output voltage after increasing the load from $10 \mathrm{~K}$ to $60 \mathrm{~K}$. The output voltage is further enhanced by increasing the number of stages. When an RF signal carries energy and information, the $\mathrm{RF}$ receiver of the energy harvester and the sensor share the same antenna. 


\section{ACKNOWLEDGEMENTS}

The authors acknowledge the technical and financial support by Universiti Teknikal Malaysia Melaka (UTeM) Short Term Grant No. PJP/2018/FKEKK(2B)/S01614.

\section{REFERENCES}

[1] K. Kotani, et al., "High-efficiency differential-drive CMOS rectifier for UHF RFIDs," IEEE J. Solid-State Circuits, vol. 44, no. 11, pp. 3011-3018, 2009.

[2] M. Stoopman, et al., "Co-design of a CMOS rectifier and small loop antenna for highly sensitive RF energy harvesters", IEEE J. Solid-State Circuits, vol. 49, no. 3, pp. 622-634, Mar 2014.

[3] M. H. Ouda, et al., "Self-biased differential rectifier with enhanced dynamic range for wireless powering", IEEE Trans. Circuits Syst. II Exp. Briefs, vol. 64, no. 5, pp. 515-519, May 2017.

[4] G. Papotto, et al., "A 90-nm CMOS threshold-compensated RF energy harvester", IEEE J. Solid-State Circuits, vol. 46, no. 9, pp. 1985-1997, Sep 2011.

[5] Z. Hameed and K. Moez, "Design of impedance matching circuits for RF energy harvesting systems," Microelectronics Journal, vol. 62. pp. 49-56, 2017.

[6] H. Dai, et al., "A review and design of the on-chip rectifiers for RF energy harvesting", Proc. IEEE IWS, pp. 1-4, Mar 2015.

[7] Y. C. Wong, et al, "Dickson Charge Pump Rectifier using Ultra-Low Power ( ULP ) Diode for BAN Applications," J. Telecommun. Electron. Comput. Eng., vol. 8, no. 9, pp. 77-82, 2016.

[8] Y. C. Wong, et al, "Reconfigurable wideband RF impedance transformer integrated with an antenna for multi-band wireless devices", Proc. Loughborough Antennas Propag. Conf., pp. 1-5, Nov 2012.

[9] Y.C. Wong, et al., "Tunable impedance matching network with wide impedance coverage for multi frequency standards RF front-end", AEU-Int J Electron Commun, vol. 82, pp. 74-82, 2017.

[10] M. Mahmoud, et al., "Efficiency improvement of differential drive rectifier for wireless power transfer applications", IEEE Conf. on intelligent syst. Modeling and simulation, no. 7, pp. 435-438, 2016.

[11] Y. Lu, et al., "A wide input range dual-path CMOS rectifier for RF energy harvesting," IEEE Trans. Circuits Syst. II Express Briefs, vol. 64, no. 2, pp. 166-170, 2017.

[12] K. Kotani and T. Ito, "High efficiency CMOS rectifier circuit with self-Vth-cancellation and power regulation functions for UHF RFIDs", Proc. IEEE Asian Solid-State Circuits Conf., pp. 119-122, Nov 2007.

[13] S. S. Hashemi, et al., "A high-efficiency low-voltage CMOS rectifier for harvesting energy in implantable devices", IEEE Trans. Biomed. Circuits Syst., vol. 6, no. 4, pp. 326-335, Aug 2012.

[14] F. Yildiz, "Potential Ambient Energy-Harvesting Sources and Techniques," J. Technol. Stud., vol. 35, no. 1, pp. 40-48, 2009.

[15] T. Le, et al., "Efficient far-field radio frequency energy harvesting for passively powered sensor networks", IEEE J. Solid-State Circuits, vol. 43, no. 5, pp. 1287-1302, May 2008.

[16] M. Xia and S. Aissa, "On the efficiency of far-field wireless power transfer", IEEE Trans. Signal Process., vol. 63, no. 11, pp. 2835-2847, Jun 2015.

[17] J. Paradiso and T. Starner, "Energy scavenging for mobile and wireless electronics", Pervasive Comput., vol. 4, no. 1, pp. 18-27, Jan 2005.

[18] S. Kim, et al., "Ambient RF energy-harvesting technologies for self-sustainable standalone wireless sensor platforms", Proc. IEEE, vol. 102, no. 11, pp. 1649-1666, Nov 2014

[19] S. Hemour and K. Wu, "Radio-frequency rectifier for electromagnetic energy harvesting: Development path and future outlook," Proc. IEEE, vol. 102, no. 11, pp. 1667-1691, 2014.

[20] K. Kotani and T. Ito, "High efficiency CMOS rectifier circuits for UHF RFIDs using Vth cancellation techniques," ASICON 2009 - Proc. 2009 8th IEEE Int. Conf. ASIC, pp. 549-552, 2009.

[21] R. E. Barnett, et al., "A RF to DC voltage conversion model for multi-stage rectifiers in UHF RFID transponders", IEEE J. Solid-State Circuits, vol. 44, no. 2, pp. 354-370, Feb 2009.

[22] U. Karthaus and M. Fischer, "Fully integrated passive UHF RFID transponder IC with 16.7-1\$mul\$W minimum RF input power", IEEE J. Solid-State Circuits, vol. 38, no. 10, pp. 1602-1608, Oct 2003.

[23] S. Percy, et al., "Supplying the power requirements to a sensor network using radio frequency power transfer", Sensors, vol. 12, no. 7, pp. 8571-8585, Jun 2014

[24] L. Xie, et. al., "Wireless power transfer and applications to sensor networks", IEEE Wireless Commun., vol. 20 , no. 4, pp. 140-145, Aug 2013.

[25] Z. Popovic, et al., "Low-power far-field wireless powering for wireless sensors", Proc. IEEE, vol. 101, no. 6, pp. 1397-1409, Jun 2013.

[26] R. P. Wicaksono, et al., "Wireless grid: Enabling ubiquitous sensor networks with wireless energy supply", Proc. IEEE Veh. Technol. Conf. (VTC-Spring), pp.15-18, May 2011

[27] J. Yoo, et al., "A $5.2 \mathrm{~mW}$ self-configured wearable body sensor network controller and a $12 \mu \mathrm{W}$ wirelessly powered sensor for a continuous health monitoring system", IEEE J. Solid-State Circuits, vol. 45, no. 1, pp. 178-188, Jan 2010.

[28] E. Sardini and M. Serpelloni, "Passive and self-powered autonomous sensors for remote measurements", Sensors, vol. 9, no. 2, pp. 1-18, Feb 2009. 


\section{BIOGRAPHIES OF AUTHORS}

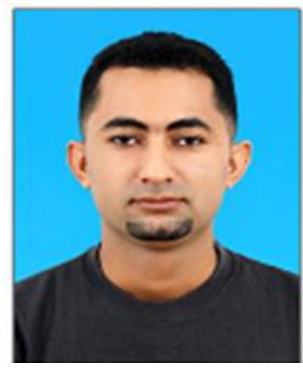

Mohammed Abdul Raheem Esmail Alselwi received the B.Eng. degree with honors in Electronics and Telecommunications from Multimedia University, Malaysia in 2013. He is currently pursuing the M. Sc. Degree at the Faculty of Electronics and Computer Engineering, Universiti Teknikal Malaysia Melaka (UTeM), Malaysia. His research interests include CMOS RF circuits, Wireless sensor networks, and Photonics.

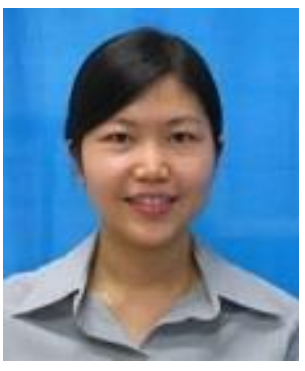

Yan Chiew Wong has completed her doctorate from The University of Edinburgh, United Kingdom on 2014. She has more than 5 years industry experience in semiconductor process design. Has previously worked at Infineon Technologies and Intel. Yan Chiew has involved intensively in the research of RF and mixed signal circuitries, adaptive impedance matching and power management control system. She has authored a number of research papers in the field of adaptive algorithm, RF reconfigurable design, EDA and etc. She has been able to successfully design and develop high voltage CMOS control chips and RF circuitries. She is equipped with both design and implementation skills. She is currently a senior lecturer in Universiti Teknikal Malaysia Melaka.

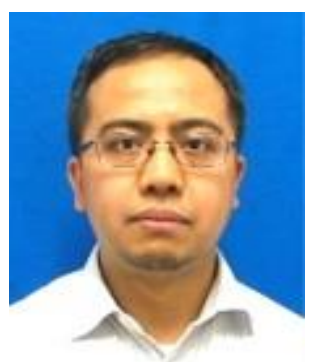

Zul Atfyi Fauzan Mohammed Napiah received his doctorate from Kanazawa University, Japan on 2017. He is currently a lecturer in Universiti Teknikal Malaysia Melaka. His research field involving field of silicon photonics and CMOS processing. 